\title{
Mycorrhizal status of forest trees grown in urban and rural environments in Poland
}

\author{
Jolanta Tyburska, Anna Frymark-Szymkowiak, Magdalena Kulczyk-Skrzeszewska, \\ Barbara Kieliszewska-Rokicka
}

Institute of Environmental Biology, Kazimierz Wielki University, Ossolińskich Al. 12, 85-093 Bydgoszcz, e-mail: jola@ukw.edu.pl

\begin{abstract}
Mycorrhizal status of mature forest trees (horse chestnut, Aesculus hippocastanum L.; white poplar, Populus alba L.; black poplar, P. nigra L.) was investigated in urban habitats under different intensity of anthropogenic pressures (restricted root zone, soil compaction, low air and soil humidity), compared to trees grown in rural environments that were used as reference biological material. Horse chestnut roots were colonized by arbuscular mycorrhizal (AM) fungi, and the two poplar species (white poplar and black poplar) were dually colonized by AM and ectomycorrhizal (ECM) fungi, regardless of habitat, except $P$. nigra grown close to a trafficked street, which had only ECM associations. The AM colonization of horse chestnut roots was higher in May than October, regardless of habitat and showed a tendency to be lower in the roots of trees from urban environments, however, only mycorrhizal frequency differed significantly between the urban habitat and the reference plot. In roots of two poplar species the intensity of AM colonization was significantly lower in disturbed urban habitats than in the rural sites. ECM colonization of white poplar did not differ between the urban and rural environments, and in black poplar roots it was lower at the city sites than in the reference plot. Significantly lower levels of available magnesium and total carbon was recorded in soils at the urban sites compared to reference plots. The concentrations of the other macro- and microelements did not differ significantly. A tendency to reduced water content in two of three urban sites was also recorded. The results indicated that mycorrhizal fungi native of urban habitats are able to develop effective symbiosis with mature tree roots and they suggested that environmental factors, such as availability of water and nutrient and carbohydrates production and allocation, are the most important factor influencing the mycorrhizal colonization of urban trees.
\end{abstract}

Keywords: arbuscular mycorrhiza, ectomycorrhiza, Aesculus hippocastanum, Populus alba, Populus nigra.

\section{Introduction}

Urban trees grown along streets, in city parks, and in other urban green spaces suffer from restricted root zone, low soil porosity and moisture, limited availability of mineral nutrients, excessive heat, and air and soil pollution. These urban environmental conditions can decrease tree root growth dynamics and alter soil chemical, physical, and biological properties.

Roots of trees are associated with mycorrhizal fungi: ectomycorrhizal (ECM) and/or arbuscular mycorrhizal (AM). Mycorrhizas are intimate associations between roots and soil fungi, penetrating root tissues to variable extents with the development of specific mycorrhizal structures. Most plants are recognized as being 'mycorrhizal' (Last et al. 1987; Smith \& Read 2008). ECM fungi (Basidiomycota and Ascomycota) develop symbiotic associations mostly with coniferous trees, such as Pinus spp., Picea spp., Abies spp., and Larix spp., but also with deciduous broadleaved trees, such as Betula spp., Carpinus spp., Fagus spp., and Quercus spp. AM fungi (Glomeromycota) form associations with roots of $80 \%$ of all terrestrial plant species including deciduous broadleaved trees, such as Acer spp., Fraxinus spp., Platanus spp., and Aesculus spp. (Smith \& Read 2008). Mycorrhizal fungi increase absorption and transport of water and mineral nutrients from the soil solu- 
tion to the symbiotic plant and, in return, obtain carbohydrates produced by the plant in photosynthesis. Mycorrhizas enhance plant growth and vitality (e.g., Perez-Moreno \& Read 2000) and can protect plants against toxic compounds (e.g., Bothe et al. 2010; Bojarczuk \& Kieliszewska-Rokicka 2010). They are particularly important for plant hosts that grow in nutrient-poor soil conditions (Smith \& Read 2008). Soil fungal species richness and abundance were found lower in the urban ecosystems compared to rural areas (Ławrynowicz 1982; Pouyat et al. 1994). Mycorrhizal fungi can be affected directly by soil $\mathrm{pH}$, low availability of nutrients, high concentration of available trace metals, elevated soil nitrogen and drought, or, indirectly, via the host plant, by reduced carbon allocation to roots after yellowing of leaves or leave loss. Decreased availability of carbohydrates may decrease production of fine roots, which can develop mycorrhizal associations (Kernaghan 2005). The environmental stress factors and fragmentation of vegetation can result in reduced availability of mycorrhizal inoculum or altered composition of mycorrhizal symbionts, compared to natural ecosystems (Newbound et al. 2010). Root growth and mycorrhiza are also negatively influenced by poor soil aeration, which is directly related to soil texture (Smith \& Read 2008).

Mycorrhizal symbioses have been studied mostly in forest ecosystems, but there are few studies on the mycorrhizal status of trees grown in cities. It has been demonstrated that mycorrhizal abundance and variability was generally lower in urban sites than in rural and forest environments in root systems of Tilia spp. (Busetti 1962; Ceruti \& Busetti 1962; Pigott 1991; Garbaye \& Churin 1996; Nielsen \& Rasmussen 1999; Timonen \& Kauppinen 2008), Quercus spp. (Keizer \& Arnolds 1994; Ochimaru \& Fukuda 2007; Karpati et al. 2011), Acer rubrum (Wiseman \& Wells 2005). Investigations of Bainard et al. (2011) concerned mycorrhizal status of 26 tree species growing in urban and rural environments revealed, that some of the species had a lower, but some had a higher AM or ECM colonization in the urban sites, and in roots of several species the difference between the urban and the rural sites was not significant.

Identification of ectomycorrhizal symbionts in roots of Tilia cordata grown along trafficked streets and in a nursery indicated that trees in the two environments had different sets of ectomycorrhizal symbionts (Timonen \& Kauppinen 2008). A question arises if mycorrhizal fungi native of urban environments are efficient symbionts of urban trees. More research is needed on mycorrhizal status of trees in different of urban habitats to increase the knowledge on the relations between specific environmental conditions and mycorrhizal abundance and variability. Therefore, the aim of this study was to investigate if mycorrhizal fungi (AM and ECM) occurring in urban ecosystems have a lower mycorrhizal efficiency compared to mycorrhizal fungi at rural sites (reference plots). To test this problem, mycorrhizal colonization of roots of mature trees grown in the city center under variable anthropogenic pressure and in rural sites was evaluated. Tree species chosen for the mycorrhiza survey (Aesculus hippocastanum L., Populus alba L., and Populus nigra L.) are commonly planted in city parks and along streets (Pauleit et al. 2002).

\section{Materials and Methods}

\subsection{Study sites}

The urban sites were located in the center of Bydgoszcz city with a population of about 358,000 , situated in northern Poland on the Brda and Vistula rivers $\left(53^{\circ} 07^{\prime} \mathrm{N}, 18^{\circ} 00^{\prime} \mathrm{E}\right)$, and included: street site located in the city center, influenced by heavy car traffic, characterized by limited open soil space under tree canopies and soil compaction (Bydgoszcz 1), the Kazimierz Wielki University (KWU), campus (Bydgoszcz 2), the Botanical Garden of KWU, an area of 2.33 ha (Bydgoszcz 3). The sites Bydgoszcz 2 and 3 were green areas in the city center. The rural environment was represented by a forest site situated in the surroundings of Bydgoszcz (Riparian forest) and the Kórnik Arboretum. The riparian forest study site was located in the Wielka Kępa Ostromecka nature reserve situated on the right bank floodplain of the Vistula River $\left(53^{\circ} 21^{\prime} \mathrm{N}, 18^{\circ} 23^{\prime} \mathrm{E}\right)$, about $0.5 \mathrm{~km}$ from the village Ostromecko. The nature reserve, officially protected since 1922 , is part of the rare elm-ash riparian forest association (Ficario-Ulmetum minoris). It covers 27.6 ha ( $2 \mathrm{~km}$ long, 50-200 m wide). The tree forest species are old poplars, with about 60 Populus nigra trees and 30 P. alba of monumental size. The Kórnik Arboretum $\left(52^{\circ} 15^{\prime} \mathrm{N}, 17^{\circ} 04^{\prime} \mathrm{E}\right)$, developed in the $19^{\text {th }}$ century, is one of the oldest collections of woody plants in Europe, covering an area of $38 \mathrm{ha}$. It is located in a countryside $25 \mathrm{~km}$ from big city Poznań and it is free of direct influence of anthropogenic stresses. It contains about 3000 species and varieties, trees and shrubs originating from various parts of the northern temperate zone.

\subsection{Sampling}

Root samples of Aesculus hippocastanum were collected in May and October 2010 in two urban study sites (Bydgoszcz 1, street sites in the city center, and Bydgoszcz 2, the KWU campus) and in a reference site in the Kórnik Arboretum. Four trees were investigated along streets and in the Kórnik Arboretum, and two trees at the KWU campus. Roots of Populus alba and P. nigra were sampled in July 2010 from trees grown in two urban sites (Bydgoszcz 1 and Bydgoszcz 3, the Botanical Garden of KWU in the city center) and in a riparian forest Wielka Kępa Ostromecka. 
Each of the poplar species at each of the study sites was represented by three trees. Root samples of the three tree species investigated were taken under canopies of mature trees, from the upper $10 \mathrm{~cm}$ of soil, about $70-100 \mathrm{~cm}$ from the tree trunk, in three sampling points located around each tree. Three samples taken under one tree were mixed and placed in one plastic bag, transported to the laboratory, and stored at $-18^{\circ} \mathrm{C}$ until use.

\subsection{Mycorrhizal colonization}

Root samples were cut into $1 \mathrm{~cm}$ pieces, and $0.25 \mathrm{~g}$ fresh weight subsamples were cleared in $10 \% \mathrm{KOH}$ and stained with trypan blue in lactoglycerol, according to Kormanik and McGraw (1982) with modifications to visualize fungal structures in the root systems. Roots of $P$. nigra and $P$. alba were cleared for $2.5 \mathrm{~h}$ and roots of $A$. hippocastanum for $1.2 \mathrm{~h}$ at $95^{\circ} \mathrm{C}$. After that, the roots were bleached in alkaline hydrogen peroxide at room temperature: poplar roots for $1 \mathrm{~h}$ and the horse chestnut roots for $2 \mathrm{~h}$. After staining in $0.05 \%$ trypan blue solution, poplar root colonization by $\mathrm{AM}$ and ECM fungi was evaluated using the intersection method (McGonigle et al. 1990) at $200 \times$ magnification. A minimum of 100 line intersections per root subsample of approximately $7 \mathrm{~cm}$ was scored for the presence of AM fungal structures (intraradical hyphae, vesicles, arbuscules, hyphal coils and spores) and ECM root tips. Approximately $100 \mathrm{~cm}$ of fine roots in total was analyzed for each sample. The results are presented as a percentage of root length colonized (\%RLC). Using this protocol, we assessed both types of mycorrhiza (AM and ECM) in the same sample. Mycorrhizal colonization of roots of $A$. hippocastanum was evaluated according to the method described by Trouvelot et al. (1986, http://www2.dijon.inra.fr/mychintec/Mycocalc-prg/download.html). At least $50 \mathrm{~cm}$ of fine roots for each subsample was scored for the presence of AM fungal structures. The parameters analyzed were: F\% (mycorrhizal frequency in the root system), M\% (intensity of the mycorrhizal colonization in the root system), A\% (arbuskule abundance in the root system), a\% (arbuskule abundance in mycorrhizal part of root fragments).

\subsection{Soil analyses}

Soil samples were sieved (mesh size $4 \mathrm{~mm}$ ), and visible plant material was removed before air drying. Macronutrients were analyzed in an extract of $0.03 \mathrm{~N}$ acetic acid. Micronutrients and $\mathrm{Pb}$ were extracted in a modified Lindsay solution, which contained the following in $1 \mathrm{dm}^{3}: 5$ g EDTAH, $9 \mathrm{ml} \mathrm{25 \%}$ ammonia, $4 \mathrm{~g}$ citric acid, and $2 \mathrm{~g}$ $(\mathrm{CH} 3 \mathrm{COO})_{2} \mathrm{Ca} 2 \mathrm{H}_{2} \mathrm{O}$ (Lindsay \& Norvell 1978; Komosa $\&$ Szewczuk 2002). After extraction, $\mathrm{S}_{-} \mathrm{SO}_{4}$ was assayed with ion-selective electrodes; $\mathrm{P}$ was assayed colorimetrically with ammonium molybdate; $\mathrm{K}, \mathrm{Ca}$, and $\mathrm{Na}$ were as- sayed with flame photometry; and chlorides were assayed nephelometrically. $\mathrm{Mg}$ and $\mathrm{Pb}$ were assayed with atomic absorption spectroscopy.

Soil $\mathrm{pH}$ was determined in 1:2.5 (w/v) soil- $\mathrm{H}_{2} \mathrm{O}$ or soil-1 $\mathrm{M} \mathrm{KCl}$ suspension. The water content was estimated at the sampling using standard operating procedure according to Hausenbuiller (1975). The soil samples were weighed first just after they were taken from study sites (wet weight) and after being dried at $105^{\circ} \mathrm{C}$ (dry weight) and the moisture content (\%) was calculated from the sample weight before and after drying.

\subsection{Statistical analysis}

Statistica version 9.0 (StatSoft Inc.) was used for the statistical data processing. Statistical differences $(p<0.05)$ in the concentrations of chemical elements in soil were established using one-way analysis of variance (ANOVA, Table 1). Two-way ANOVA was used to examine the levels of significance $(\mathrm{p}<0.05)$ of the factors (site, time, and their interactions) on mycorrhizal colonization. Mean values of root and soil parameters were separated using Tukey's honestly significantly difference test. The data were transformed when necessary to achieve normality, according to the Bliss formula (Snedecor \& Cochran 1976). The figures present non-transformed data.

\section{Results}

\subsection{Mycorrhizal colonization}

All trees of $A$. hippocastanum investigated in the urban environment in Bydgoszcz and in the rural area (the Kórnik Arboretum) were colonized by AM fungi. The AM fungi developed typical mycorrhizal structures: mycorrhizal intraradical hyphae, vesicles, arbuscules, and hyphal coils (Fig. 1). The frequency $(\% \mathrm{~F})$ of the AM structures was high in roots of all $A$. hippocastanum trees studied (ranged from $58 \%$ in the samples taken in October along city streets up to $75 \%$ in samples taken in May in the Kórnik Arboretum), and differ significantly between urban and non-urban environments only in May $(\mathrm{p} \leq 0.05)$. The average intensity of mycorrhizal colonization in the root systems of $A$. hippocastanum (M\%) was higher in the root samples taken in May than in October; however, the differences between the sampling dates and the study sites were not significant (Tables 2, 3). Arbuscules, the fungal structures exchanging nutrients between the mycobiont and the phytobiont, were developed in the roots of $A$. hippocastanum at each study site; however, in the rural environment (Kórnik Arboretum), they were observed in May and in the urban environment (Bydgoszcz), they were present in October (Table 2). Moreover, the highest arbuscule abundance in the root sys- 

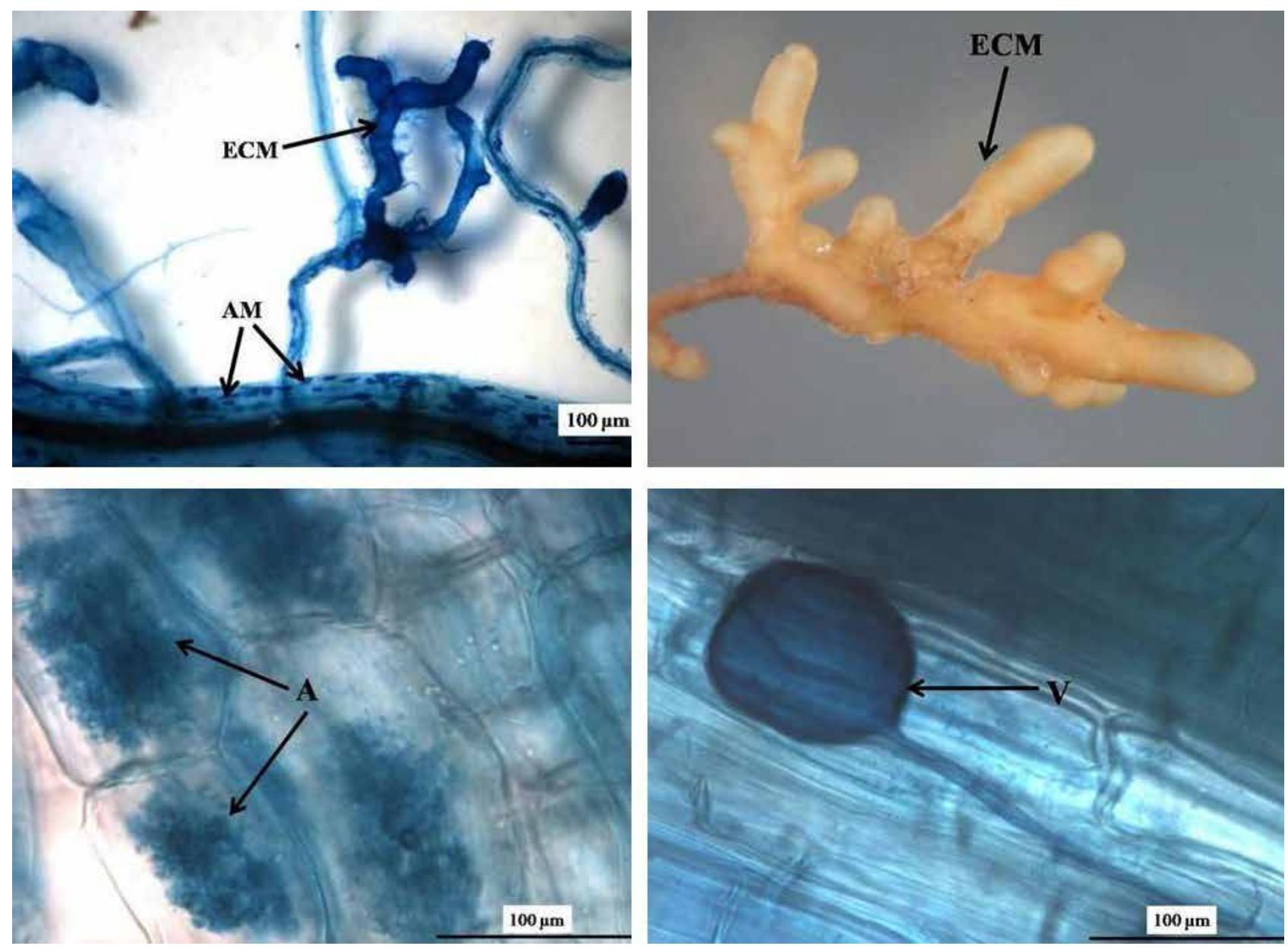

Figure 1. Dual ectomycorrhizal (ECM) and arbuscular mycorrhizal (AM) colonization of Populus nigra roots (top - left), ectomycorrhiza of Populus alba (top - right) and AM colonization of Aesculus hippocastanum roots (bottom). A - arbuscules, $\mathrm{V}-$ vesicles

tem $(\mathrm{A} \%)$, and the arbuscule abundance in mycorrhizal root fragments $(\mathrm{a} \%)$ were found in roots of trees growing along heavily trafficked street in Bydgoszcz (Bydgoszcz 1) (Table 2). The arbuscules abundance differed significantly between the urban and the rural study sites: A\% - in May and $\mathrm{a} \%$ - in October (Tables 2, 3).

Roots of both poplar species ( $P$. nigra, $P$. alba) were dually colonized by AM and ECM fungi. The average percentage of AM and ECM colonization was generally higher in the riparian forest than in the urban environment in Bydgoszcz (Fig. 2A, B). ECM colonization of fine roots of $P$. nigra was significantly higher in the riparian forest $(28.1 \%$ RLC) than in the two urban sites located at a trafficked street (Bydgoszcz 1) and the Botanical Garden (Bydgoszcz 3) (9.25 and 12.1\% RLC, respectively). Colonization of the poplar roots by AM fungi varied significantly between the study sites, from $69 \%$ RLC in the riparian forest and 39\% RLC in the Botanical Garden to 0 in the street sites (Fig. 2A).
The ECM colonization roots of $P$. alba ranged from $27 \%$ RLC in the Botanical Garden of KWU (Bydgoszcz 3 ) and $36.5 \%$ RLC in roots of the trees grown close to the trafficked street (Bydgoszcz 1) up to 57\% RLC in the riparian forest Wielka Kępa Ostromecka (Fig. 2B); however, the differences were not significant. The average colonization of $P$. alba roots by AM fungi exceeded $20 \%$ RLC in the Botanical Garden and in the riparian forest, and was significantly lower in roots of trees grown at street sites (2.2\% RLC) (Fig. 2B).

\subsection{The chemical and physical parameters of soil}

The soil $\mathrm{pH}_{(\mathrm{H} 2 \mathrm{O})}$ values ranged from 7.33 to 7.76 , classified as neutral to slightly alkaline (Table 1). Concentrations of most of the macro- and micronutrients analyzed and soil conductivity did not differ significantly between the urban sites and the reference plots. Significant differences were found only in the concentrations of available 
Table 1. Chemical and physical variables of soils in urban habitats (Bydgoszcz 1 - street sites, Bygdoszcz 2 - campus of the Kazimierz Wielki University (KWU), Bydgoszcz 3 - Botanical Garden of KWU), in rural environment - the Kórnik Arboretum, and the riparian forest. Significant differences between sites are indicated by different letters $(n=3)$

\begin{tabular}{|c|c|c|c|c|c|}
\hline & $\begin{array}{c}\text { Bydgoszcz } \\
1\end{array}$ & $\begin{array}{c}\text { Bydgoszcz } \\
2\end{array}$ & $\begin{array}{c}\text { Bydgoszcz } \\
3\end{array}$ & $\begin{array}{c}\text { Kórnik } \\
\text { Arboretum }\end{array}$ & Riparian forest \\
\hline $\mathrm{pH}\left(\mathrm{H}_{2} \mathrm{O}\right)$ & 7.76 & 7.38 & 7.33 & 7.44 & 735 \\
\hline $\mathrm{pH}(\mathrm{KCl})$ & 7.27 & 6.98 & 7.20 & 6.95 & 6.60 \\
\hline$P\left(\mathrm{mg} \cdot 100 \mathrm{~g}^{-1}\right)$ & 4.60 & 5.05 & 3.45 & 5.45 & 4.7 \\
\hline $\mathrm{K}\left(\mathrm{mg} \cdot 100 \mathrm{~g}^{-1}\right)$ & 19.10 & 14.65 & 22.35 & 7.85 & 11.4 \\
\hline $\mathrm{Ca}\left(\mathrm{mg} \cdot 100 \mathrm{~g}^{-1}\right)$ & 147.15 & 79.05 & 165.20 & 117.95 & 167.8 \\
\hline $\operatorname{Mg}\left(\mathrm{mg} \cdot 100 \mathrm{~g}^{-1}\right)$ & $15.90^{\mathrm{a}}$ & $8.00^{\mathrm{a}}$ & $21.25^{\mathrm{ab}}$ & $33.60^{\mathrm{b}}$ & $36.5^{\mathrm{b}}$ \\
\hline $\mathrm{S}-\mathrm{SO}_{4}\left(\mathrm{mg} \cdot 100 \mathrm{~g}^{-1}\right)$ & 1.00 & 0.75 & 1.80 & 1.50 & 1.5 \\
\hline $\mathrm{Cl}\left(\mathrm{mg} \cdot 100 \mathrm{~g}^{-1}\right)$ & 2.35 & 1.95 & 1.60 & 1.50 & 2.0 \\
\hline $\mathrm{Na}\left(\mathrm{mg} \cdot 100 \mathrm{~g}^{-1}\right)$ & 3.10 & 1.35 & 2.90 & 1.80 & 3.2 \\
\hline $\mathrm{Pb}\left(\mathrm{mg} \mathrm{kg}^{-1}\right)$ & 23.47 & 13.77 & 25.01 & 28.79 & 13.12 \\
\hline $\mathrm{C}(\%)$ & $0.37^{\mathrm{ab}}$ & $0.25^{\mathrm{a}}$ & $0.80^{\mathrm{b}}$ & $0.70^{\mathrm{b}}$ & $0.47^{\mathrm{ab}}$ \\
\hline N (\%) & 0.145 & 0.445 & 0.56 & 0.28 & 0.36 \\
\hline $\mathrm{C} / \mathrm{N}$ & 2.87 & 1.79 & 1.74 & 2.51 & 1,30 \\
\hline $\mathrm{EC}\left(\mathrm{mS} \mathrm{cm}^{-1}\right)$ & 0.20 & 0.15 & 0.25 & 0.26 & 0.37 \\
\hline Water content $(\%)$ & $9.23^{\mathrm{a}}$ & $12.97^{\mathrm{a}}$ & $30.43^{b}$ & $16.09^{\mathrm{a}}$ & $20.00^{\mathrm{ab}}$ \\
\hline
\end{tabular}

Table 2. Mycorrhizal colonization of roots of Aesculus hippocastanum grown in urban environments (Bydgoszcz 1 - a heavily trafficted street, Bydgoszcz 2 - a university campus) and in rural habitat (Kórnik Arboretum) in May and October 2010. $\mathrm{F} \%$ - frequency of mycorrhiza in the root system, M\% - intensity of the mycorrhizal colonization in the root system, $\mathrm{A} \%$ - arbuscule abundance in the root system, a\% - arbuscule abundance in mycorrhizal part of root fragments

\begin{tabular}{|c|c|c|c|c|c|c|}
\hline & \multicolumn{2}{|c|}{ Bydgoszcz 1 } & \multicolumn{2}{c|}{ Bydgoszcz 2 } & \multicolumn{2}{c|}{ Kórnik } \\
\hline & May & October & May & October & May & October \\
\hline $\mathrm{F} \%$ & 63.33 & 58.33 & 73.33 & 66.67 & 75.00 & 70.83 \\
\hline $\mathrm{M} \%$ & 14.46 & 8.28 & 21.48 & 1.68 & 11.38 & 7.28 \\
\hline $\mathrm{A} \%$ & 0 & 1.05 & 0 & 0.27 & 0.31 & 0 \\
\hline $\mathrm{a} \%$ & 0 & 46.68 & 0 & 13.67 & 8.57 & 0 \\
\hline
\end{tabular}

Table 3. Results of ANOVA testing the influence of study term and site on mycorrhizal colonization of roots of Aesculus hippocastanum (L.): frequency of mycorrhiza in root system (F\%), intensity of mycorrhizal colonization in the root system (M\%), arbuscule abundance in the root system (A\%), arbuscule abundance in mycorrhizal part of root fragments (a\%), for overall study terms and sites and for each study term separately

\begin{tabular}{|c|c|c|c|c|c|c|c|c|}
\hline & \multicolumn{2}{|c|}{$\mathrm{F} \%$} & \multicolumn{2}{|c|}{ M\% } & \multicolumn{2}{|c|}{$\mathrm{A} \%$} & \multicolumn{2}{|c|}{$a \%$} \\
\hline & $\mathrm{F}$ & $\mathrm{p}$ & $\mathrm{F}$ & $\mathrm{p}$ & $\mathrm{F}$ & $\mathrm{p}$ & $\mathrm{F}$ & $\mathrm{p}$ \\
\hline \multicolumn{9}{|l|}{ Overall } \\
\hline Study term & 0.11 & 0.75 & 3.65 & 0.10 & 1.49 & 0.268 & 1.39 & 0.28 \\
\hline Site & 0.23 & 0.80 & 0.14 & 0.87 & 0.34 & 0.722 & 0.36 & 0.71 \\
\hline Study term ${ }^{\times}$Site & 0.01 & 0.98 & 1.04 & 0.41 & 3.92 & 0.082 & 1.68 & 0.26 \\
\hline \multicolumn{9}{|l|}{ In each study term } \\
\hline Study term 1 & & & & & & & & \\
\hline Site & 1.38 & 0.37 & 0.61 & 0.60 & $14.42^{\mathrm{a}}$ & $0.029^{\mathrm{a}}$ & 4.95 & 0.11 \\
\hline \multicolumn{9}{|l|}{ Study term 2} \\
\hline Site & $43.15^{\mathrm{a}}$ & $0.02^{\mathrm{a}}$ & 0.47 & 0.68 & 10.47 & 0.087 & 18.28 & 0.05 \\
\hline
\end{tabular}

a- significant effect 

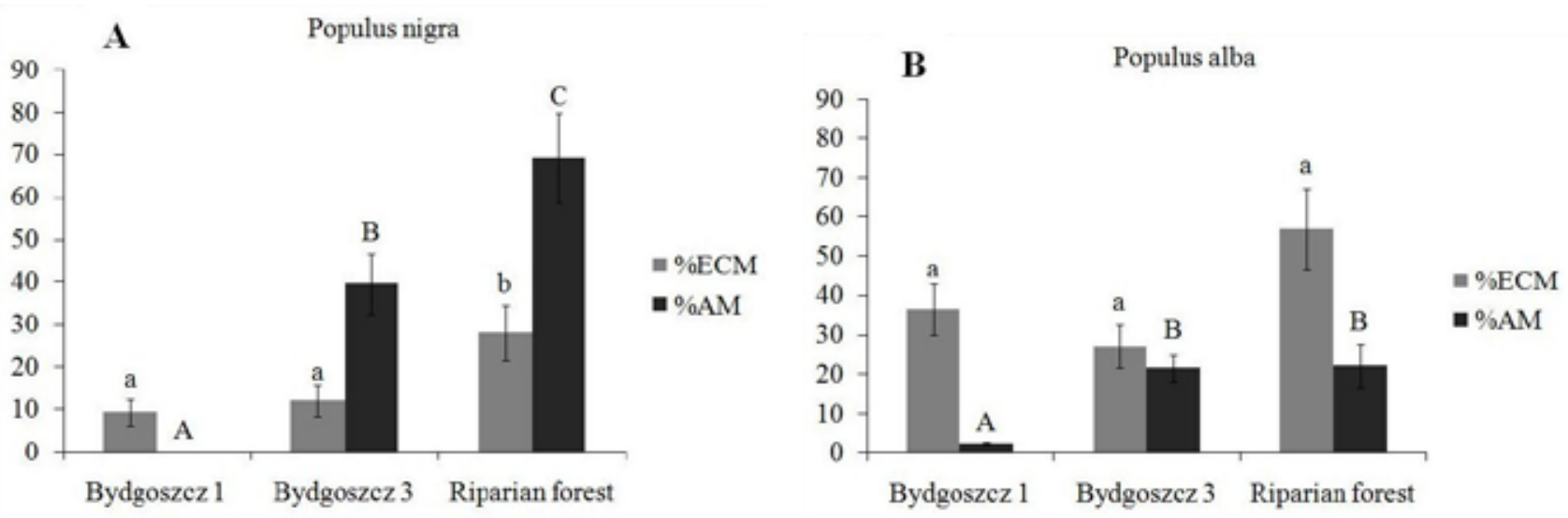

Figure 2. Mycorrhizal colonization (\%RLC $=$ root length colonized) of poplars grown in urban environments (Bydgoszcz $1-$ Bydgoszcz streets, Bydgoszcz 3 - Botanical Garden of KWU) and in the riparian forest (Wielka Kępa Ostromecka) by ectomycorrhizal (ECM) and arbuscular mycorrhizal (AM) fungi. A - Populus nigra, B - P. alba $(\mathrm{n}=3)$

magnesium and total carbon. Soil samples from the three urban sites in Bydgoszcz were characterized by significantly lower concentrations of available $\mathrm{Mg}$ than the rural environments (Kórnik Arboretum and the riparian forest). Two urban sites (Bydgoszcz 1, the street sites and Bydgoszcz 2, the University campus) had a significantly lower percentage of total $\mathrm{C}$ than the soils from the rural environment (Kórnik Arboretum) and the Botanical Garden in Bydgoszcz (Bydgoszcz 3). The concentration of $\mathrm{C}$ in soil at the riparian forest was not significantly different from the three urban soils and the soil from Kórnik Arboretum (Table 1). In the two urban sites (Bydgoszcz 1, Bydgoszcz 2) and in the rural sites lower soil humidity was recorded compared to the soil in the Botanical Garden (Bydgoszcz 3) (Table 1). A variability in the concentration of available $\mathrm{Pb}$ between the study sites (13.12-28.8 $\mathrm{mg}$ $\mathrm{kg}^{-1} \mathrm{~d}$. wt.) was found; however, the differences were not significant (Table 1).

\section{Discussion}

We investigated mycorrhizal status of mature trees grown in variable urban environments, along trafficked streets and in green areas located in the center of a big city, compared to reference plots located in rural areas. Our results showed that all the trees investigated developed mycorrhizal symbioses typical for each species (Aesculus hippocastanum, AM, and Populus spp., dual, ECM and AM) regardless of habitat. The results also showed a tendency to lower mycorrhizal colonization in roots of trees growing in the urban environments compared to reference plots; however, only in a few cases did the average mycorrhizal colonization differ significantly between habitats.

The presence of all typical AM structures (arbuscules, vesicles, intraradical and extramatrical hyphae) in roots of A. hippocastanum both in the rural and the urban environments, particularly the high abundance of arbuscules proved the functioning of the symbiosis AM fungi-A. hippocastanum in degraded soils at city sites. Our results showed also a few significant differences in mycorrhizal colonization of $A$. hippocastanum between the urban and the rural site Similarly Bainard et al. (2011), who investigated 26 tree species growing in urban and rural environments in Canada in terms of mycorrhizal abundance, found that 10 of the 26 species had a significantly lower AM colonization in urban environments compared to rural environments, two among seven tree species had significantly lower ECM colonization when growing in urban conditions. A. hippocastanum was among the species that did not differ significantly in mycorrhizal level regardless of urban or rural habitat. Lower intensity of AM colonization of roots of Acer rubrum growing in an urban environment was reported by Wiseman and Wells (2005). One of the reasons for the lower average AM intensity in tree roots could be an insufficient access of roots to the symbiotic fungal propagules. This possibility has been demonstrated directly by Stabler et al. (2001), Cousins et al. (2003), and Bills and Stutz (2009), who observed a lower number of fungal spores and a lower species diversity at sites situated near streets and housing estates compared to areas surrounding metropolitan cities.

Our study, demonstrated that the differences in mycorrhizal colonization of $A$. hippocastanum were most af- 
fected by sampling times (May and October) than study sites. A higher intensity (M\%) was recorded in May than in October, both in urban and in rural habitats; however, arbuscule formation differed between study sites. In the rural area, the arbuscules were abundant in May, but in the urban environment, they were abundant in October. Arbuscules start to form approximately 2 days after AM fungal hyphae penetrate the root, and they are the major site of exchange between the fungus and host (Brundrett et al. 1985). Allocation of carbon from shoot to root is a key condition for mycorrhiza development. Differences in arbuscule abundance observed in this study may be the result of a different physiological status of horse chestnut at the urban and rural sites at sampling date and of variable external conditions, such as soil moisture, aeration, and temperature, the important factors influencing the formation of arbuscules (Khan 1995). Seasonal changes in AM fungal hyphae colonization have been reported for different plants, such as winter wheat (Mohammad et al. 1998), alpine herbs (Ruotsalainen et al. (2002), grapevine (Lutgen et al. 2003). Environmental conditions influence the plant growth and functioning and the activity of soil microbiota, including mycorrhizal fungi. The data reported by Bainard et al. (2011) were average for samples taken only once, in June, from different urban environments (included city parks, streetscapes, private residential property in different cities) and rural sites (forested areas) in Canada. We may expect, that mycorrhiza survey in several growing seasons could indicate more precise the differences between the urban and rural habitats.

In this study the colonization level of $P$. nigra and $P$. alba, dually colonized by both ECM and AM fungi, was generally lower in the urban environment in Bydgoszcz than in the forest habitat. However, the levels of colonization (AM\% and $\mathrm{ECM} \%$ ) and the response of mycorrhiza to environmental conditions varied between the poplar species. The exception was for AM colonization, which was significantly decreased in trees of both poplar species growing close to a street with heavy traffic (site Bydgoszcz 1). Similarly, Khasa et al. (2002), Gehring et al. (2006) and Karliński et al. (2010) reported that different poplar species and hybrids varied in their proportions of ECM/ AM colonization. Karliński et al. (2010) identified poplar host genotype as the most important factor determining mycorrhizal status, modified strongly by environmental conditions. Gehring et al. (2006) suggested that the poplar genotype and soil humidity influence the proportion AM/ ECM colonization. In our study, the ECM colonization of $P$. nigra was lower in the urban environment than in the riparian forest; however, no significant differences were recorded in roots of $P$. alba between the two environments. Bainard et al. (2011) observed variable responses of AM/ ECM colonization under urban conditions of three poplar species ( $P$. deltoides, $P$. grandidentata, $P$. tremuloides).
Two of the species, $P$. deltoides and $P$. tremuloides, grown in urban environments had significantly lower ECM colonization than in rural environments. Simultaneously, $P$. deltoides was the only tree species among 26 studied that had a significantly higher arbuscular mycorrhizal colonization in urban than in rural environments. Lower intensity of ECM colonization has been identified in roots of Tilia cordata (Nielsen \& Rasmussen 1999; Timonen \& Kauppinen 2008) and Quercus rubra (Wiseman \& Wells 2005; Karpati et al. 2011) growing in urban habitats. These authors also reported a lower variability in ECM fungi composition. Although our results, in agreement with other (i.e. Nielsen \& Rasmussen 1999; Bainard et al. 2011; Karpati et al. 2011) indicated a general lower mycorrhizal (AM and ECM) colonization in urban compared to rural areas, we don't identify yet the most important factor implicated in the regulation of mycorrhiza, however water availability may influence the mycorrhizal development and maintainace. Experiments conducted under controlled conditions could help in better understanding the relationships between selected environmental variables and the mycorrhizal status of trees.

In conclusion, this study showed that the mycorrhizal fungi, native of urban environment, can be effective symbionts of mature Aesculus hippocastanum, Populus alba and $P$. nigra, able to develop abundant mycorrhizal colonization in urban green areas, and reduced mycorrhiza in strongly disturbed urban habitats. ECM fungi seem to be more tolerant to the urban environment than AM fungi, however the mycorrhizal abundance in tree roots and the tolerance to adverse environmental conditions is strongly influenced by tree genotype. The symbiotic activity of native mycorrhizal fungi in disturbed urban sites can be certainly supported by basic tillage practices of urban trees.

\section{Acknowledgments}

This work was financially supported by Kazimierz Wielki University (statutory project). We thank Natalia Głowska MSc for excellent technical support concerning poplar mycorrhiza visualization.

\section{References}

Bainard L. D., Klironomos J. N. \& Gordon A. M., 2011, The mycorrhizal status and colonization of 26 tree species growing in urban and rural environments, Mycorrhiza 21: 91-96.

Bills R. J. \& Stutz J. C., 2009, AMF associated with non-indigenous plants at urban and desert sites in Arizona, [in:] C. Azcon-Aguilar, J. M. Barea, S. Gianinazzi and V. Gianinazzi-Pearson (eds.), Mychorrhizas - Functio- 
nal Processes and Ecological Impact, Springer-Verlag, Berlin Heidelberg: 207-220.

Bojarczuk K. \& Kieliszewska-Rokicka B., 2010, Effect of ectomycorrhiza on $\mathrm{Cu}$ and $\mathrm{Pb}$ accumulation in leaves and roots of silver birch (Betula pendula Roth.) seedlings grown in metal-contaminated soil, Water, Air and Soil Pollution 207: 227-240.

Bothe H., Turnau K. \& Regvar M., 2010, The potential role of arbuscular mycorrhizal fungi in protecting endangered plants and habitats, Mycorrhiza 20(7): 445-457.

Brundrett M. C., Piché Y. \& Peterson R. L., 1985, A developmental study of the early stages in vesicular-arbuscular mycorrhiza formation, Canadian Journal of Botany 63: 184-194.

Busetti L., 1962, Sulle micorrize dei tigli (about mycorrhizas of Tilia), Allionia 8: 45-54.

Ceruti A. \& Busetti L., 1962, Sulle simbtosi mycorrhiza tratiglie Boletus subtomentosus, Russula grisea, Balsamia platysopora, Hysterangium clathroides (About mycorrhizal symbiosis of Tilia trees and Boletus subtomentosus, Russula grisea, Balsamia platyspora and Hysterangium clathroides), Allionia 8: 55-66.

Cousins J. R., Hope D., Gries C. \& Stutz J. C., 2003, Preliminary assessment of arbuscular mycorrhizal fungal diversity and community structure in an urban ecosystem, Mycorrhiza 13: 319-326.

Garbaye J. \& Churin J. L., 1996, Effect of ectomycorrhizal inoculation at planting on growth and foliage quality of Tilia tomentosa, Journal of Arboriculture 22: 29-34.

Gehring C. A., Mueller R. C. \& Whitham T. G., 2006, Environmental and genetic effects on the formation of ectomycorrhizal and arbuscular mycorrhizal associations in cottonwoods, Oecologia 149: 158-164.

Hausenbuiller R. L., 1975, Soil Science Principles and Practice, 4th printing 1975, Wm. C. Brown Co., Dubuque, Iowa: 90.

Karliński L., Rudawska M., Kieliszewska-Rokicka B. \& Leski T., 2010, Relationship between genotype and soil environment during colonization of poplar roots by mycorrhizal and endophytic fungi, Mycorrhiza 20: 315-324.

Karpati A. S., Handel S. N., Dighton J. \& Horton T. R., 2011, Quercus rubra - associated ectomycorrhizal fungal communities of disturbed urban sites and mature forests, Mycorrhiza 21: 537-547.

Keizer P. J. \& Arnolds E., 1994, Succession of ectomycorrhizal fungi in roadside verges planted with common oak (Quercus robur L.) in Drenthe, the Netherlands, Mycorrhiza 4: 147-159.

Kernaghan G., 2005, Mycorrhizal diversity: cause and effect, Pedobiologia 49: 511-520.

Khan A. G., 1995, Effects of various soil environmental stresses on the occurrence, distribution and effectiveness of VA mycorrhizae, Biotropia 8: 39-44.
Khasa P. D., Chakravarty P., Robertson A., Thomas B. R. \& Dancik B. P., 2002, The mycorrhizal status of selected poplar clones introduced in Alberta, Biomass and Bioenergy 22(2): 99-104.

Komosa A. \& Szewczuk A., 2002, Effect of soil potassium level and different potassium fertilizer forms on nutritional status, growth and yield of apple trees in the first three years after planting, Journal of Fruit and Ornamental Plant Research 10: 41-54.

Kormanik P. P. \& McGraw A. C., 1982, Quantification of vesicular-arbuscular mycorrhizae in plant roots, [in:] N.C. Schenck (ed.), Methods and principles of mycorrhizal research, Amer Phytopathol Soc., St. Paul: 37-45.

Last F. T., Dighton J. \& Mason P. A., 1987, Successions of sheathing mycorrhizal fungi, Trends in Ecology and Evolution 2: 157-161.

Lindsay W. L. \& Norvell W. A., 1978, Development of a DTPA soil test for zinc, iron, manganese, and copper, Soil Science Society America Journal 42: 421-428.

Lutgen E. R., Muir-Clairmont D., Graham J. \& Rillig M. C., 2003, Seasonality of arbuscular mycorrhizal hyphae and glomalin in a western Montana grassland, Plant and Soil 257: 71-83.

Ławrynowicz M., 1982, Macrofungal flora of Łódź [in:] R. Bornkamm, J. A. Lee, M. R. D. Seaward (eds.), Urban Ecology, The Second European Ecological Symposium, Berlin 8-12 September, Blackwell Scientific Publications, Oxford, London, Edinburgh, Boston, Melbourne: 41-47.

McGonigle T. P., Miller M. H., Evans D. G., Fairchild G. L. \& Swan J. A., 1990, A new method, which gives an objective measure of colonization of roots by vesicular-arbuscular mycorrhizal fungi, New Phytologist 115: 495-501.

Mohammad M. J., Pan W. L. \& Kennedy A. C., 1998, Seasonal mycorrhizal colonization of winter wheat and its effect on wheat growth under dry land field conditions, Mycorrhiza 8(3): 139-144.

Newbound M., McCarthy M. A. \& Lebel T., 2010, Fungi and the urban environment: A review, Landscape and Urban Planning 96: 138-145.

Nielsen J. S. \& Rasmussen H. N., 1999, Mycorrhizal status and morphotype diversity in Tilia cordata - a pilot study of nurseries and urban habitats, Acta Horticulturae 496: 451-459.

Ochimaru T. \& Fukuda K., 2007, Changes in fungal communities in evergreen broad-leaved forests across a gradient of urban to rural areas in Japan, Canadian Journal of Forest Research 37(2): 247-258.

Pauleit S., Jones N., Garcia-Martin G., Garcia-Valdecantos J. L., Rivière L. M., Vidal-Beaudet L., Bodson M. \& Randrup T. B., 2002, Tree establishment practice in towns and cities - results from a European survey, Urban Forestry \& Urban Greening 1: 83-96. 
Perez-Moreno J. \& Read D. J., 2000, Mobilization and transfer of nutrients from litter to tree seedlings via the vegetative mycelium of ectomycorrhizal plants, New Phytologist 145: 301-309.

Pigott C. D., 1991, Tilia cordata Miller, Journal of Ecology 79: 1147-1207.

Pouyat R. V., Parmelee R. W. \& Carreiro M. M., 1994, Environmental effects on forest soil invertebrate and fungal densities in oak stands along an urban-rural land use gradient, Pedobiologia 38: 385-399.

Ruotsalainen A. L., Väre H. \& Vestberg M., 2002, Seasonality of root fungal colonization in low-alpine herbs, Mycorrhiza 12(1): 29-36.

Smith S. E. \& Read D. J., 2008, Mycorrhizal Symbiosis, Academic Press, London.

Snedecor W. \& Cochran W. G., 1976, Statistical methods, 6th ed., The Iowa State University Press, Ames: $327-$ 329.
Stabler L. B., Martin C. A. \& Stutz J. C., 2001, Effect of urban expansion on arbuscular mycorrhizal fungal mediation of landscape tree growth, Journal of Arboriculture 27: 193-202.

Timonen S. \& Kauppinen P., 2008, Mycorrhizal colonisation patterns of Tilia trees in street, nursery and forest habitats in southern Finland, Urban Forestry \& Urban Greeting 7: 265-276.

Trouvelot A., Kough J. L. \& Gianinazzi-Pearson V., 1986, Measure du taux de mycorrhization VA d' un système rediculaire. Researche de mèthodes d' estimation ayant une signification fonctionnelle, [in:] V. Gianinazzi-Pearson, S. Gianinazzi (eds), Physiological and Genetical Aspects of Mycorrhizae, INRA, Paris, France: 217-221. Wiseman P. E. \& Wells C., 2005, Soil inoculum potential and arbuscular mycorrhizal colonization of Acer rubrum in forested and developed landscapes, Journal of Arboriculture 31: 296-302. 